\title{
Measurement of Blood Loss during Adenotonsillectomy in Children and Factors Affecting It
}

\author{
D. Manikandan, F. Musarrat, A. P. Preetham, R. Anjali \\ Department Of ENT, Southern Railway Headquarters Hospital, Chennai, India \\ Email: cmcmani@gmail.com
}

Received 9 Arpil 2015; accepted 5 May 2015; published 12 May 2015

Copyright (C 2015 by authors and Scientific Research Publishing Inc.

This work is licensed under the Creative Commons Attribution International License (CC BY). http://creativecommons.org/licenses/by/4.0/

(c) (i) Open Access

\section{Abstract}

This prospective study was done at the Southern Railway Headquarters Hospital, Ayanavaram, Chennai to measure the intraoperative blood loss during adenotonsillectomy and to assess the factors affecting it. Since blood volume in children is low, even a small loss will result in dreaded complications, so blood loss measurement in paediatric surgery is important. Adenotonsillectomy is the most common surgery performed in the field of otolaryngology, so blood loss measurement is essential in this surgery. In the study, 50 children who underwent adenotonsillectomy, by conventional dissection and snare method for tonsillectomy and curette method for adenoidectomy, were evaluated for operative blood loss. This study was conducted over a 1 year period, from June 2013 to June 2014. Both gravimetric method and blood volume studies were used to measure the operative blood loss. The estimated blood loss by gravimetric method was $94.35 \mathrm{ml}$, whereas the actual blood loss by blood volume studies was $90.57 \mathrm{ml}$ and the average blood loss was $92.46 \mathrm{ml}$. The youngest child who was operated was 4 years old and the oldest child was 15 years old. The minimum blood loss was $40.30 \mathrm{ml}$ and the maximum was $278.46 \mathrm{ml}$. In our series, operative blood loss was dependent on fibrosis of tonsil and the grade of the tonsil. There was no significant correlation between age and sex of the patient and the surgical skills.

\section{Keywords}

Adenotonsillectomy, Blood Loss, Dissection and Snaring, Tonsillectomy, Adenoidectomy

\section{Introduction}

Adenotonsillectomy is one of the most commonly performed surgeries in the field of ENT. Since most of the

How to cite this paper: Manikandan, D., Musarrat, F., Preetham, A.P. and Anjali, R. (2015) Measurement of Blood Loss during Adenotonsillectomy in Children and Factors Affecting It. Case Reports in Clinical Medicine, 4, 151-156. 
patients undergoing adenotonsillectomy are children, even small amounts of blood loss may lead to severe complications. No single technique of adenotonsillectomy can be recommended as an ideal method. Conventional dissection and method remains the procedure of choice in many centers. Operative blood loss depends upon sex, age, operating surgeon, grade of the tonsil and presence of fibrosis.

There are many studies which show bleeding as the most common complication of adenotonsillectomy and various methods to reduce blood loss [1]-[7], but only very few studies have dealt with measurement of adenotonsillectomy blood loss [1] [3]-[7]. It is difficult to accurately measure the operative blood loss in adenotonsillectomy [1]. Various methods of blood loss measurement have been suggested. These include subjective estimation which is highly unreliable and objective methods such as gravimetric methods (swab weighing, weighing the patient, etc.), automated blood loss meter based on electrolyte conductivity, calorimetric method and measuring the radioactivity of blood [8].

\section{Materials and Methods}

Patients presenting with recurrent adenotonsillitis in the age group of 4 to 15 years old who were posted for adenotonsillectomy by conventional dissection and snaring method were included in the study. Children below 4 years old were not included in the study because they have low blood volume. On admission, all the children were weighed and their hemoglobin and hematocrit were measured using automated hematology analyzer. Their tonsillar grade was measured.

Tonsillar enlargement can be graded according to subjective measurement [9].

Grade 1 Tonsils are in the tonsillar fossa.

Grade 2 Tonsils are visible behind the anterior pillar, and occupying 50\% of oropharyngeal space.

Grade 3 Tonsils occupy $50 \%$ to $75 \%$ of oropharyngeal space.

Grade 4 Tonsils occupy more than $75 \%$ of oropharyngeal volume.

Other investigations were also done for anesthesia fitness. Before starting the procedure, a good amount of cotton and ribbon gauze were taken and sterilized. The suction bottle, including the rubber tube, was cleaned and emptied completely. A known quantity of saline was taken in the bowl and used for intermittent suction in order to prevent blockage of suction tube. All the cases were operated under general anaesthesia with an orotracheal intubation after inducing with propofol and fentanyl. Vecuronium was used as the muscle relaxant and anesthesia maintained with sevoflourane. Glycopyrrolate was used to decrease the salivary secretion. During surgery, all the blood lost was collected in the suction bottle. After adenoidectomy, a length of ribbon gauze piece was packed in the nasopharynx. Tonsillectomy was then performed and the bleeding points were immediately cauterized or clamped and ligated. The tonsillar fossae were packed with cotton balls. Once the tonsils were snared off, these were squeezed thoroughly into the gauze or cotton ball and the tonsils were discarded. After ligating the bleeding points, the nostrils and the nasopharynx were suctioned. Then all the saline taken in the bowl was suctioned into the suction bottle. The suction tube was raised above the level of suction bottle to ensure that all the fluid was emptied into the suction bottle. The quantity of fluid in suction bottle was then measured by pouring it into the measuring cylinder and the quantity was measured. Postoperative hemoglobin and hematocrit were also measured. Blood loss was calculated by taking the average of actual blood loss and estimated blood loss [10].

Estimated blood loss was calculated by following method.

Number of cotton balls used $=\mathrm{a}$

Approximate amount of blood a cotton ball had $=2.5 \mathrm{ml}$

Amount of blood in cotton balls (c) $=2.5 \times$ (a)

No of gauzes used $=\mathrm{b}$

Approximate amount of blood a gauze had $=10 \mathrm{ml}$

Amount of blood in gauzes $(\mathrm{d})=10 \times(\mathrm{b})$

Quantity of blood in cotton balls \& gauze $(\mathrm{A})=(\mathrm{c}+\mathrm{d})$

Amount of fluid (Blood and known quantity of saline) collected in the suction bottle $=\mathrm{e}$

Amount of saline used $=\mathrm{f}$

Quantity of blood in suction bottle $(B)=(e-f)$

Total quantity of blood lost (Estimated blood loss) $=\mathrm{A}+\mathrm{B}$. 
Actual blood loss is calculated from a modification of the Gross formula [11].

$$
\text { Actual blood loss }=\text { BV }\{\operatorname{Hct}(\mathrm{i})-\operatorname{Hct}(\mathrm{f}) / \operatorname{Hct}(\mathrm{m})\}
$$

BV: Blood volume.

Blood volume is calculated from the body weight by using following formula.

$$
\left(\text { Blood volume }=\text { Body weight in } \mathrm{Kgs} \times 70 \mathrm{mlkg}^{-1}\right)^{4}
$$

Hct (i): Initial hematocrit

Hct (f): Final hematocrit

Hct (m): Mean hematocrit

Average blood loss is calculated from actual blood loss and estimated blood loss.

\section{Results}

A total of 50 children who underwent adenotonsillectomy by conventional method were selected. The proportion of children aged below 10 years old and 10 years old and above was $46 \%$ and $54 \%$ respectively. The proportion of males and females was $60 \%$ and $40 \%$ respectively. $76 \%$ of surgeries were performed by junior residents and $24 \%$ by consultants. The proportion of tonsil grade 2 and grade 3 were $40 \%$ and $60 \%$ respectively out of which $26 \%$ were fibrosed. The mean actual blood loss calculated from patient's blood volume and pre and post operative hematocrit was $90.57 \mathrm{ml}$. The mean estimated blood loss calculated from number of cotton balls, gauze used, and amount of blood in suction bottle was $94.35 \mathrm{ml}$. The mean average blood loss calculated from the average of actual blood loss and estimated blood loss was $92.46 \mathrm{ml}$.

Mean blood loss in children less than and more than 10 years old were $85.29 \mathrm{ml}$ and $98.57 \mathrm{ml}$ respectively. Even though mean average blood loss was $13.28 \mathrm{ml}$ more in 10 years old and above age group, this difference was not statistically significant $(\mathrm{P}>0.05)$ (Figure 1$)$.

In males the mean blood loss was $98.48 \mathrm{ml}$ and in females it was $88.45 \mathrm{ml}$. Though the blood loss was 10.03 $\mathrm{ml}$ more in males, it was not statistically significant $(\mathrm{P}>0.05)$ (Figure 2).

Compared to consultant group, where the blood loss was 75.26, mean value of blood loss was $22.64 \mathrm{ml}$ more in junior resident group. In the hands of the junior residents, the blood loss was $97.89 \mathrm{ml}$, but this difference was not statistically significant (Figure 3).

The mean blood loss in grade 2 tonsil was $111.94 \mathrm{ml}$, whereas in grade 3, it was $79.48 \mathrm{ml}$. Grade 2 tonsil has $32.46 \mathrm{ml}$ more blood loss than grade 3 which was statistically significant $(\mathrm{P}<0.05)$ (Figure 4).

The mean blood loss in fibrosed tonsil was $120.19 \mathrm{ml}$, and without fibrosis was $82.72 \mathrm{ml}$. The mean difference was $37.48 \mathrm{ml}$ and it was statistically significant $(\mathrm{P}<0.05)$ (Figure 5).

\section{Discussion}

Blood loss estimation is rarely done in adenotonsillectomy, but a review of literature indicates that mortality associated with adenotonsillectomy is almost invariably associated with heavy bleeding. If the blood loss at adenotonsillectomy were always measured, and its importance appreciated by reference to the equivalent percentages of blood volume at different ages, catastrophes would no doubt be less common [12]. Routine blood loss measurements enable a more scientific assessment and comparison of different surgeries and methods to reduce blood loss.

In children physiological mechanisms are less adaptable. So, even a moderate blood loss will lead to hemodynamic instability and complications [1]. Thus the estimation of blood loss for nearly all pediatric surgeries and a more widespread appreciation of the equivalent quantities for adults and children would do much to reduce dangerous imbalance of blood volume [12].

By using independent $T$ test, various parameters were correlated with blood loss. Though mean blood loss difference between children less than and more than 10 years old was 13.28, this difference was not statistically significant $(\mathrm{P}>0.05)$. So, age in children and the blood loss is not significant and patient's age doesn't have an impact on adenotonsillectomy blood loss. This finding correlates with Holden and Maher's [2] and Shalom's [13] study on blood loss measurement. In a study conducted by KC Prasad and SC Prasad [1], it was shown that the 


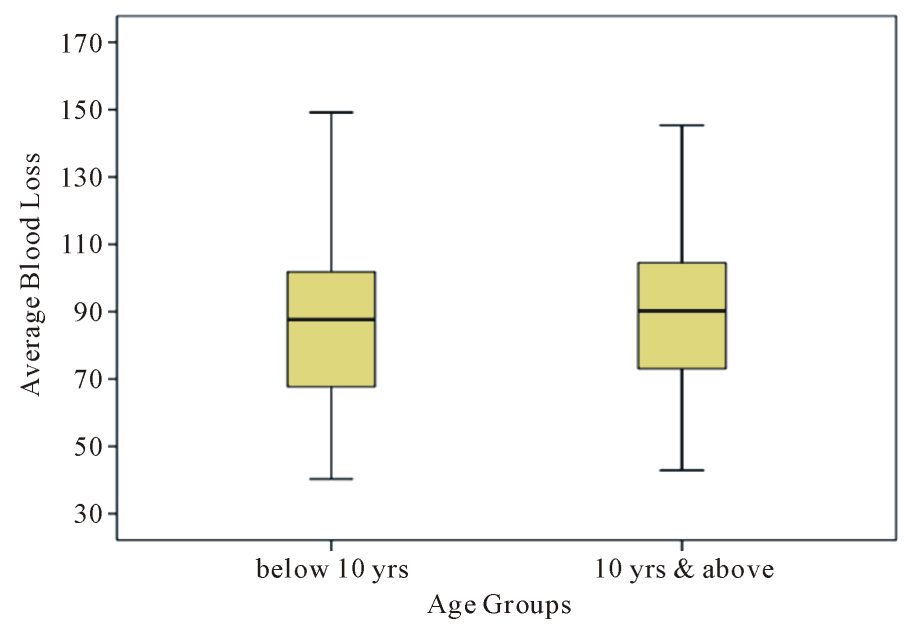

Figure 1. Box and whisker plot shows the relation between age groups and average blood loss.

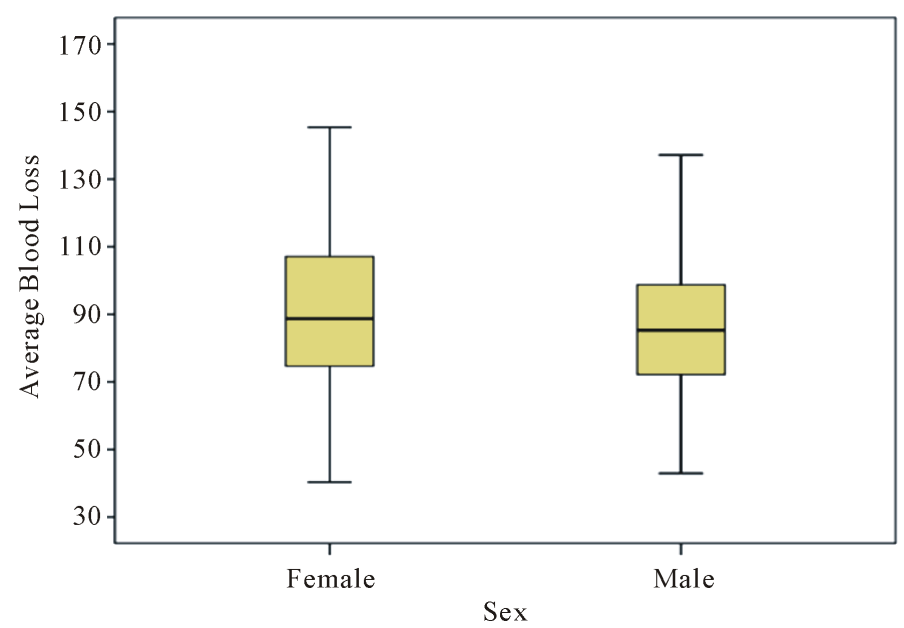

Figure 2. Box and whisker plot shows the relation between gender and average blood loss.

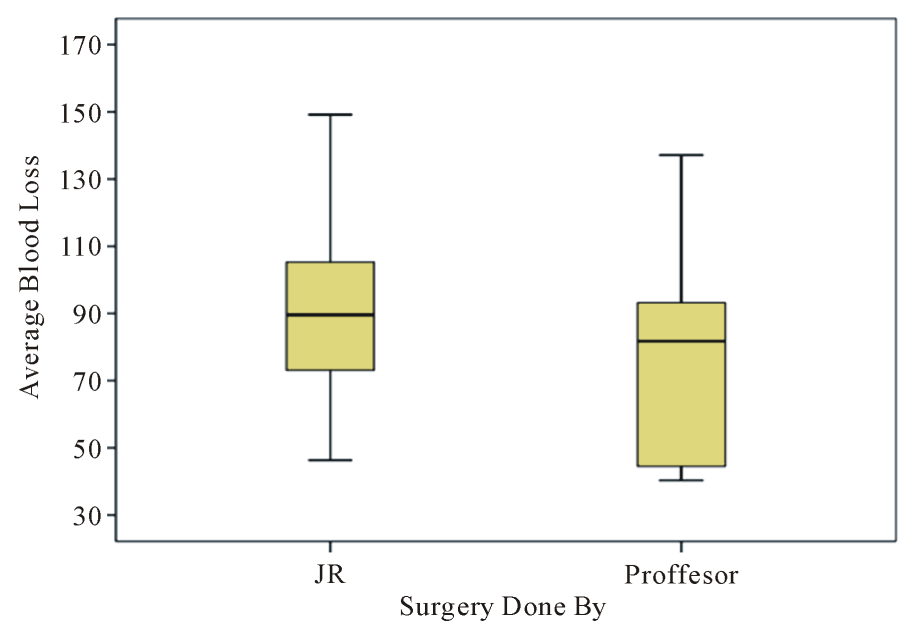

Figure 3. Box and whisker plot shows the relation between done by and average blood loss. 


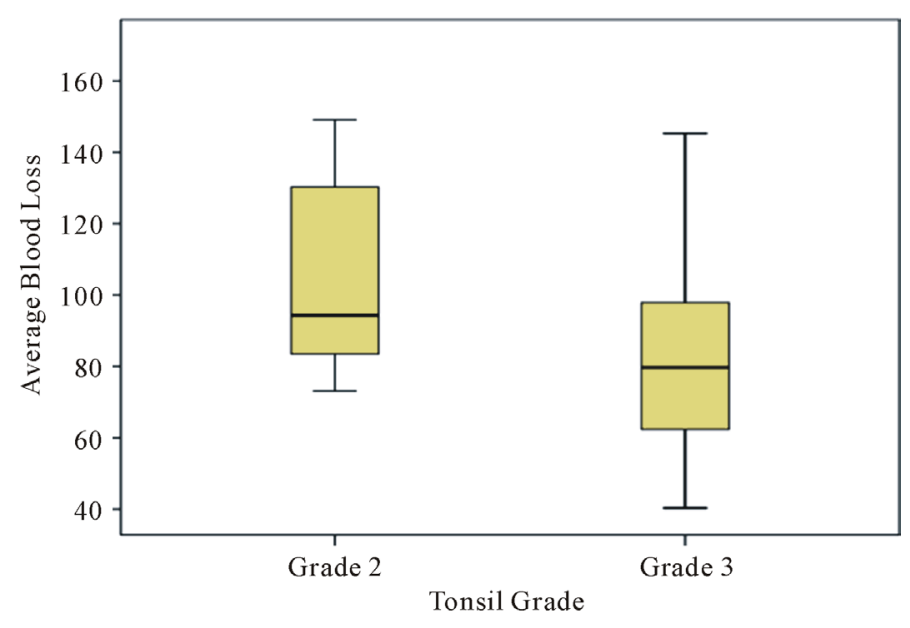

Figure 4. Box and whisker plot shows the relation between tonsil grade and average blood loss.

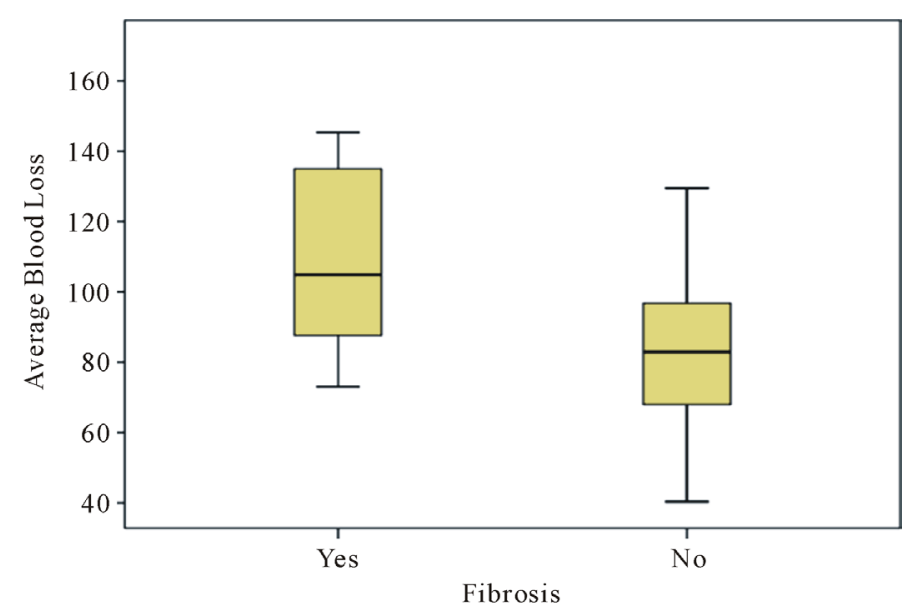

Figure 5. Box and whisker plot shows the relation between fibrosis and average blood loss.

older the child is, the greater the blood loss is. Though the difference in mean blood loss between males and females was $10.03 \mathrm{ml}$, it was not statistically significant $(\mathrm{P}>0.05)$. So, sex difference and the blood loss are not significant, and the patient's gender doesn't have an impact on adenotonsillectomy blood loss. In Shalom's study, he didn't find any significant relation between blood loss and sex of the patient. In our study also the blood loss was not statistically significant between the two genders. In contrast, KC Prasad and SC Prasad's study showed more blood loss in male patients. Compared to consultant group, mean value of blood loss was $22.64 \mathrm{ml}$ more in junior resident group but this difference was not statistically significant. So, the surgeon doesn't have an impact on adenotonsillectomy blood loss. This finding differs from the finding of the study of Sporell et al. [3], where surgical technique and surgical skill have a considerable influence. In Davenport and Barr's study [12], the loss of blood in adenotonsillectomy by each surgeon varied considerably, but was fairly constant for each surgeon and independent of experience. Grade 2 tonsil has $32.46 \mathrm{ml}$ more blood loss than grade 3 tonsil, which is statistically significant $(\mathrm{P}<0.05)$. So, tonsillar grade and blood loss are significant, and the tonsillar grade has an impact on adenotonsillectomy blood loss. There was no other study correlating the grade and tonsillectomy blood loss. The mean difference in blood loss between tonsil with and without fibrosis was $37.48 \mathrm{ml}$ and it was statistically significant $(\mathrm{P}<0.05)$. Holder and Maher's study showed significant blood loss in fibrosed tonsil.

The studies by Callanan et al. [4], Boliston and Upton [5], Shalom, De Reyner [6], Maier and Bogue [7] have shown that the blood loss during tonsillectomy and adenotonsillectomy was more than $100 \mathrm{ml}$. In Spoerell, 
Ruggles [14] and Prasad's study, the blood loss during adenotonsillectomy was comparatively less than tonsillectomy alone. Since the tonsillectomy alone was performed in adults, blood loss was more in tonsillectomy alone group than adenotonsillectomy group. The mean of actual blood loss was $90.57 \mathrm{ml}$ and the mean of estimated blood loss was $94.35 \mathrm{ml}$. The average blood loss of these two parameters was $92.46 \mathrm{ml}$. Blood loss measurement by gravimetric method and laboratory method didn't vary significantly. In study of Lee et al., by comparing gravimetric and laboratory methods, highly significant correlation was found between laboratory and gravimetric methods, supporting the use of weight measurement as accurate and less time consuming or costly when compared to the laboratory method [15]. In Johar and Smith's study, no significant correlation was found between gravimetric and laboratory methods [16].

\section{Conclusion}

The study was conducted on a total of 50 patients who underwent adenotonsillectomy by conventional dissection and snare method. Both calorimetric and repeated volume determination methods were used to assess the intraoperative blood loss. The average amount of blood loss in adenotonsillectomy was $92.46 \mathrm{ml}$. The amount of blood loss was more with increasing age, females, and the case operated by junior residents, but it was not statistically significant. Statistically significant blood loss was noted in grade 2 tonsillar enlargement and in fibrosed tonsil.

\section{References}

[1] Prasad, K.C. and Prasad, S.C. (2011) Assessment of Operative Blood Loss and the Factors affecting it in Tonsillectomy and Adenotonsillectomy. Indian Journal of Otolaryngology and Head \& Neck Surgery, 63, 343-348. http://dx.doi.org/10.1007/s12070-011-0268-9

[2] Holden, H.B. and Maher, J.J. (1965) Some Aspects of Blood Loss and Fluid Balance in Paediatric Adenotonsillectomy. British Medicine Journal, 2, 1349-1351. http://dx.doi.org/10.1136/bmj.2.5474.1349

[3] Spoerell, W.E., Hersey, W.L. and Greenway, R.A. (1960) Blood Loss during Tonsillectomies in Children. Canadian Medical Association Journal, 82, 1265-1267.

[4] Callanan, V., Curran, A.J., Smyth, D.A. and Gormley, P.K. (1995) The Influence of Bismuth Subgallate and Adrenaline Paste upon Operating Time and Operative Blood Loss in Tonsillectomy. The Journal of Laryngology \& Otology, 109, 206-208. http://dx.doi.org/10.1017/S0022215100129706

[5] Boliston, T.A. and Upton, J.J. (1980) Infiltration with Lignocaine and Adrenaline in Adult Tonsillectomy. The Journal of Laryngology \& Otology, 94, 1257-1259. http://dx.doi.org/10.1017/S0022215100090071

[6] De Reynier, J.P. (1959) Hemorrhage during Tonsillectomy. Pract Otorhinolaryngologica, 21, 18-23.

[7] Maier, H.L. and Bogue, C.R. (1970) Measurement of Blood Loss during Tonsillectomy and Adenoidectomy. AORN Journal, 11, 62-66.

[8] Thornton, J.A., Saynor, R., Schroeder, H.G., Taylor, D.G. and Verel, D. (1963) Estimation of Blood Loss with Particular Reference to Cardiac Surgery: Description of a Method. British Journal of Anaesthesia, 35, 91-99. http://dx.doi.org/10.1093/bja/35.2.91

[9] CahaliI, M.B., de Paula Soares, C.F., da Silva Dantas, D.A. and Formigoni, G.G.S. (2011) Tonsil Volume, Tonsil Grade and Obstructive Sleep Apnea: Is There Any Meaningful Correlation? Clinics, 66, 1347-1351. http://dx.doi.org/10.1590/S1807-59322011000800007

[10] Eipe, N. and Ponniah, M. (2006) Perioperative Blood loss Assessment-How Accurate? Indian Journal of Anaesthesia, 50, 35-38.

[11] Gross, J.B. (1983) Estimating Allowable Blood Loss: Corrected for Dilution. Anesthesiology, 58, 277-280. http://dx.doi.org/10.1097/00000542-198303000-00016

[12] Davenport, H.T. and Barr, M.N. (1963) Blood Loss during Paediatric Operations. Canadian Medical Association, 89, 1309-1313.

[13] Shalom, A.S. (1964) Blood Loss in Ear, Nose and Throat Operations. The Journal of Laryngology \& Otology, 78, 734756. http://dx.doi.org/10.1017/S0022215100062691

[14] Ruggles, R.L. (1960) Blood Loss during Adenoidectomy and Tonsillectomy Measured with Radioisotopes. Annals of Otology, Rhinology \& Laryngology, 69, 360-374. http://dx.doi.org/10.1177/000348946006900206

[15] Lee, M.H., Ingvertsen, B.T., Kirpensteign, J., Jensen, A.L. and Kristensen, A.T. (2006) Quantification of Surgical Blood Loss. Veterinary Surgery, 35, 388-393. http://dx.doi.org/10.1111/j.1532-950X.2006.00162.x

[16] Johar, R.S. and Smith, R.P. (1993) Assessing Gravimetric Estimation of Intraoperative Blood Loss. Journal of Gynecologic Surgery, 9, 151-154. http://dx.doi.org/10.1089/gyn.1993.9.151 